\title{
EDUCOMUNICAÇÃO AMBIENTAL: COMPARANDO AÇÕES REALIZADAS NO ESPAÇO ESCOLAR E NO PERCURSO DE AULA-PASSEIO EM UMA UNIDADE DE CONSERVAÇÃO COSTEIRA
}

\author{
Jucicleide Gomes da Silva Souza ${ }^{1}$ \\ Elineí Araújo de Almeida ${ }^{2}$
}

Resumo: O presente artigo analisa como ações educomunicativas medeiam o ensino-aprendizagem no ambiente escolar e em seu exterior, ao utilizar atividades pedagógicas diversificadas, entre elas aula passeio, mapa ambiental e jornal mural, como práticas socioculturais para a apropriação de novos saberes voltados às interações homem-meio. Esta pesquisa foi realizada em uma escola pública de ensino fundamental, situada em uma Área de Proteção Ambiental (APA) na região costeira do Rio Grande do Norte, com os alunos de $4^{\circ}$ e $5^{\circ}$ ano. Utilizou-se a pesquisa-ação participativa como metodologia. Esses agentes sociais participaram desta proposta como parceiros, e não como objetos de pesquisa. Os resultados comprovaram a necessidade de desenvolver práticas pedagógicas, envolvendo ações educomunicativas para além do chão da escola, promovendo a interação e vivência dos alunos com o meio a partir do espaço onde moram.

Palavras-chave: Aula contextualizada. Meio Ambiente. Redes comunicativas.

\section{ENVIRONMENTAL EDUCOMMUNICATION: COMPARING ACTIONS TAKEN IN SCHOOL AND ALONG THE WAY OF A CLASS TRIP IN A COASTAL CONSERVATION AREA}

Abstract: This paper analyzes how educommunication actions mediate teaching and learning in the school environment and its exterior, using a variety of educational activities, including class trip, environmental map and wall newspaper, as sociocultural practices for the appropriation of new knowledge towards man-environment interactions. This research was conducted in a public elementary school located in an Environmental Protection Area (EPA) in the coastal region of Rio Grande do Norte, Brazil, with $4^{\text {th }}$ and $5^{\text {th }}$-grade students. Participatory action research was the methodology used. Those social workers participated in this proposal as partners, not as objects of research. The results confirmed the need to develop educational practices involving educommunication actions beyond the school grounds, providing students with interaction and experience with the environment starting in the space where they live.

Keywords: Contextualized class. Environment. Communication networks.

EDUCOMUNICACIÓN AMBIENTAL: COMPARANDO ACCIONES REALIZADAS EN EL ESPACIO ESCOLAR Y EN EL RECORRIDO DE CLASEPASEO EN UNA UNIDAD DE CONSERVACIÓN COSTERA

\footnotetext{
${ }^{1}$ Pedagoga e Mestre em Desenvolvimento e Meio Ambiente na Universidade Federal do Rio Grande do Norte(UFRN), Brasil, jucicleidesouza@gmail.com

${ }^{2}$ Professora do Departamento de Botânica, Ecologia e Zoologia e do Programa de Pós Graduação em Desenvolvimento e Meio Ambiente Universidade Federal do Rio Grande do Norte(UFRN), elinei.araujo@gmail.com
} 
Resumen: El presente artículo analiza cómo acciones educomunicativas medían la enseñanzaaprendizaje en el ambiente escolar y en su exterior, al utilizar actividades pedagógicas diversificadas, entre ellas clase paseo, mapa ambiental y periódico mural, como prácticas socioculturales para la apropiación de nuevos saberes dirigidos a las interacciones hombremedio. Esta investigación se realizó en una escuela pública de enseñanza fundamental, situada en un Área de Protección Ambiental (APA) en la región costera de Rio Grande do Norte, con los alumnos de $4^{\circ}$ y $5^{\circ}$ año. Se utilizó la investigación-acción participativa como metodología. Estos agentes sociales participaron de esta propuesta como colaboradores, y no como objetos de investigación. Los resultados comprobaron la necesidad de desarrollar prácticas pedagógicas, envolviendo acciones educomunicativas más allá del suelo de la escuela, promoviendo la interacción y vivencia de los alumnos con el medio a partir del espacio donde viven.

Palabras clave: Clase contextualizada. Medio Ambiente. Redes comunicativas.

\section{Introdução}

Atualmente, a educação requer práticas sociais que levem à pesquisa, à indagação, à inquietude e à reflexão. Nessa perspectiva, a educomunicação fornece instrumentos por meio das redes comunicativas visando estabelecer negociações de sentidos no momento em que se apropria dos discursos e produz outros, manifestando os aprendizados dos sujeitos participantes no processo educativo (SOARES, 2002, p. 16). O papel do professor/comunicador, nesse contexto, é focalizar os conteúdos ligados uns aos outros, legitimando ações que formem e construam conhecimentos articulados e atendam às expectativas dos alunos. Desse modo, implementa-se uma comunicação transformadora e a cultura se torna mais consciente, libertária e educativa (FREIRE, 1967, p. 41).

As práticas e metodologias da Educomunicação encontram-se assentadas em objetivos que capacitam e estimulam o desenvolvimento de experiências envolvendo atividades em que os recursos e tecnologias da comunicação são indispensáveis para a formação de receptores críticos e comunicadores participativos. Vivências direcionadas à produção de mensagens linguísticas para serem emitidas, veiculadas e recebidas constituem processos de comunicação dialógicos, alternativos e independentes. Concretiza-se, nessa perspectiva, o desenvolvimento de projetos como foi proposto por Freinet (1998), ao elaborar jornais para o estímulo à reflexão e intercomunicação grupal.

Esses tipos de atividades, além de capacitarem para uma leitura crítica da comunicação e exercitarem competências comunicativas dos indivíduos envolvidos, favorecem processos reflexivos, ajudando a desenvolver a percepção sobre a realidade e as próprias identidades (FERRÉS, 1996; MARTIRANI, 2005).

É nesse sentido que se insere a Educomunicação Ambiental, uma prática educativa mediatizada e redimensionadora do papel tanto do professor quanto dos alunos, tendo nas aulas as bases para a integração efetiva entre a educação e a comunicação, que na perspectiva da Educação Ambiental (EA) convergem para uma experiência enriquecedora (BELLONI, 2008, p. 54).

No tocante à EA, os Parâmetros Curriculares Nacionais - PCN (BRASIL, 1997, p. 26) orientam, como um dos objetivos do ensino fundamental, que o aluno seja capaz de "perceber-se integrante, dependente e agente transformador do ambiente, identificando seus elementos e as interações entre eles, contribuindo ativamente para a melhoria do meio ambiente". 
A EA faz parte dos temas transversais dentro dos Parâmetros Curriculares Nacionais e deve ser trabalhada com o corpo discente no processo de ensino-aprendizagem, juntamente com a sociedade, já que esta pode partir para procedimentos diante da realidade em que vive, buscando sempre meios que possam possibilitar-lhe o desenvolvimento de uma consciência crítica e respeito ao meio ambiente natural. Segundo Leff (2001, p. 151):

O texto dos PCN's [sic] reitera que o ensino da Educação Ambiental deve considerar as esferas globais e locais, favorecendo tanto a compreensão dos problemas ambientais em termos macros (político, econômico, social e culturais) como em termos regionais.

Nesse sentido, as questões ambientais devem ser tratadas na escola em todas as suas esferas curriculares, permeando a prática docente para envolver os diversos momentos de aprendizagem, incluindo toda a comunidade escolar na proteção e cuidado com seu próprio meio.

Em recente pesquisa, Torres (2008) concluiu que cerca de $82 \%$ da população da APA Jenipabu não sabe o que é uma Área de Proteção Ambiental, enquanto 50\% não sabe que reside dentro dessa área. Segundo a autora:

Os resultados desse e de outros trabalhos apontam para a necessidade de implantação de um projeto de educação ambiental para as escolas da APA de Genipabu focando os estudantes do ensino fundamental e objetivando a criação de futuros moradores sensibilizados com as questões ambientais e que eles possam ser multiplicadores das boas práticas ambientais em seus domicílios e em toda a comunidade. (TORRES, 2008, p. 48).

Considerando esses dados, o presente artigo analisa como ações educomunicativas realizadas no espaço escolar e em seu exterior medeiam o ensino-aprendizagem, ao envolverem elementos que desencadeiam a comunicação ambiental, utilizando-se de múltiplos aspectos pedagógicos.

Especificamente, os objetivos desta pesquisa incluem: analisar nuances da leitura feita por alunos acerca da realidade da uma Área de Proteção Ambiental (APA) onde estão inseridos, no que diz respeito aos recursos disponíveis e à necessidade de implementação de atividades educomunicativas, como sugerem as diretrizes da Estratégia Nacional de Comunicação e Educação Ambiental (BRASIL, 2009); investigar como ações educomunicativas aplicadas em escola localizada no interior de uma Unidade de Conservação Ambiental de uso sustentável tornam-se elementos de sensibilização que mobilizam a comunidade escolar; e obter dados para colaborar com a implementação de projetos e ações continuadas no interior e no entorno da APA Jenipabu, Rio Grande do Norte.

\section{Material e métodos}

\section{Local de estudo}

A Escola Municipal Ricardo Afonso de Lima (EMRAL) está localizada na Praia de Santa Rita. É uma instituição pública municipal, sob os cuidados administrativos da prefeitura de Extremoz, Rio Grande do Norte. Atualmente funciona nos turnos matutino e vespertino, com um 
total de 60 alunos matriculados nas séries iniciais do Ensino Fundamental. Essa unidade escolar está inserida na Área de Proteção Ambiental Jenipabu, conhecida pela comunidade local como APAJ.

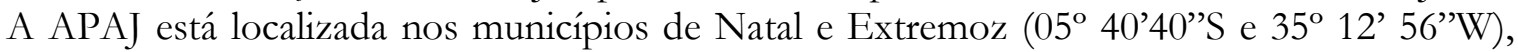
com uma superfície total de 1.881 hectares. Segundo o Decreto $n^{\circ} 19.139$, de 5 de junho de 2006, a APA Jenipabu foi criada no dia 17 de maio de 1995 com o objetivo de ordenar o uso, proteger e preservar: a) os ecossistemas de praia, mata atlântica e manguezal; b) lagoas, rios e demais recursos hídricos; c) dunas; e d) espécies vegetais e animais.

Em face das suas belezas paisagísticas, características geológicas, geomorfológicas e posicionamento geográfico, com a proximidade da capital, a área se apresenta como uma das mais importantes para o turismo do Rio Grande do Norte. Por possuir uma grande variedade de recursos naturais e ambientais - dunas fixas e móveis, lagoas, rio, praias e mangues - de expressivas potencialidades turísticas e importância econômica, era previsível a sua destinação como polo turístico de interesse econômico (IDEMA, 2009).

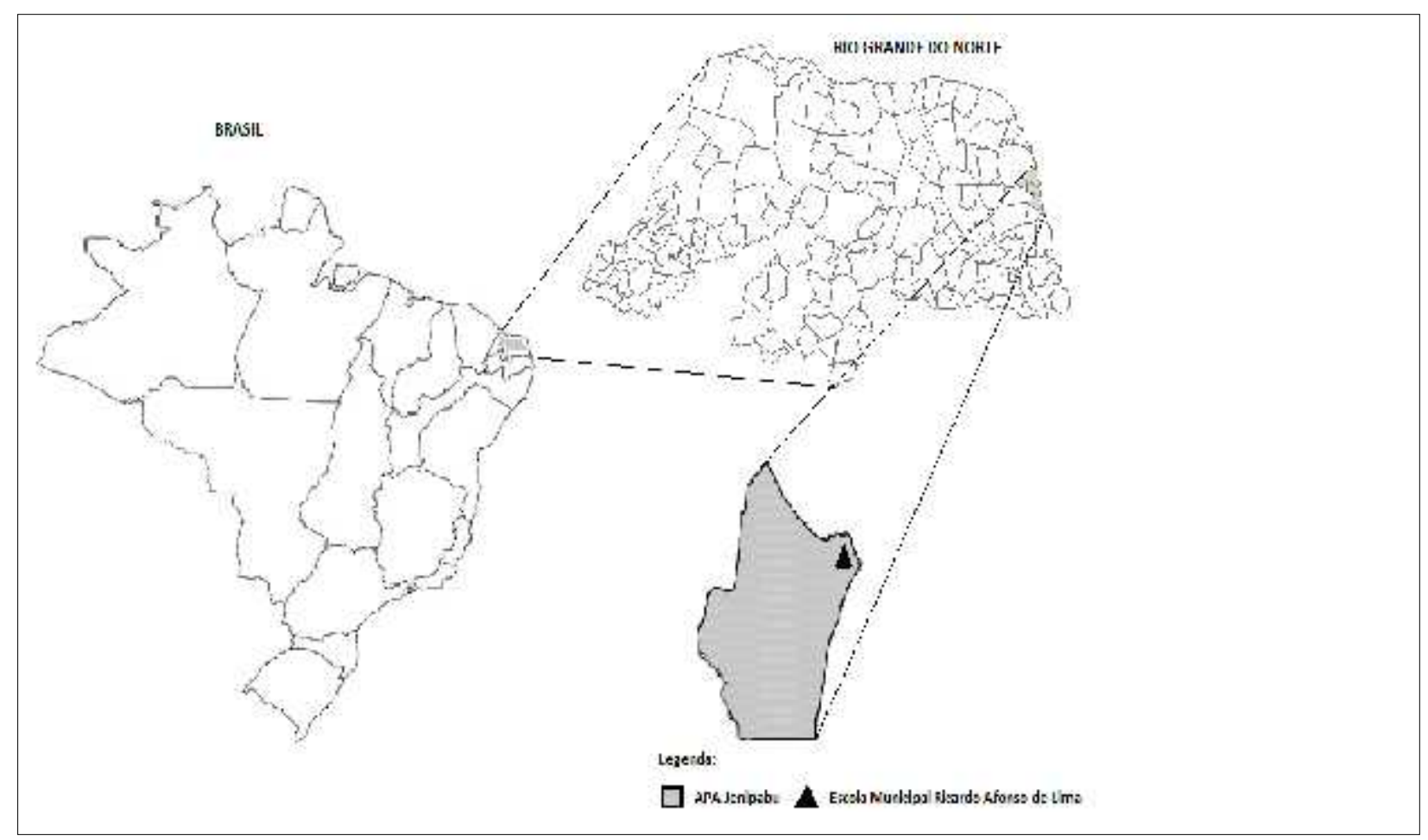

Figura 1. Mapa de localização da APA Jenipabu e Escola Municipal Ricardo Afonso de Lima, localizada no distrito de Santa Rita, Extremoz/RN. Fonte: Nascimento e Araújo de Almeida (2012).

Esta pesquisa foi realizada com base na pesquisa-ação participativa, seguindo os princípios abordados em Cazoto e Tozoni-Reis (2008), os quais se fundamentam em Brandão (1981), Demo (2004) e Thiollent (1984).

A princípio, houve uma aproximação com a comunidade escolar para discutir com professores, pais e alunos a possibilidade de participarem em uma ação de conhecimento da Área de Proteção Ambiental Jenipabu (APAJ), na qual se verificou que os conteúdos informativos sobre meio ambiente ainda eram incipientes na trajetória educativa de muitos. Em consequência dessa 
percepção, direcionamentos pedagógicos para ações educomunicativas foram colocados como metas a serem atingidas no processo investigativo. Destacam-se a construção de mapas ambientais, realização de aula-passeio, confecção de jornal mural e aplicação de oficinas.

Do ponto de vista metodológico, o modo de investigação eleito, envolvendo a análise de intervenções de práticas pedagógicas emancipadoras (produção de desenhos, realização de aulapasseio e confecção de jornal mural), garante a possibilidade de um tema ser tratado segundo seu significado para todos os sujeitos que participam desta proposta educativa como colaboradores, isto é, tornam-se parceiros, e não mais objetos de pesquisa. Por ter como característica prioritária o envolvimento e participação dos agentes sociais na produção de conhecimentos sobre sua própria vida, a metodologia pode ser organizada em torno de determinadas ações educativas (THIOLLENT, 1984).

De acordo com Brandão (2003), as pesquisas participantes são de tal forma apropriadas para a construção de conhecimentos sobre o vivido que, para investigar processos educativos envolvendo crianças, podem constituir-se em poderosos instrumentos pedagógicos, pois:

Se elas vivem o que através de incontáveis investigações imaginamos conhecer cientificamente, por que não perguntar a elas o que sabem sobre seu próprio modo de vida? Por que não dialogar com e entre elas sobre o que vivem e o que desejam, antes de investigá-las ou de realizar "experimentos" sobre elas? Por que não aprender a viver pesquisas com elas em vez de apenas realizar investigações experimentais sobre elas? Romântico? O que pensar, porém, do longo tempo em que as mulheres não podiam (ou não deviam) realizar estudos sobre o corpo, a vida e a própria identidade? (BRANDÃO, 2003, p. 12).

Inserida na pesquisa qualitativa, a pesquisa-ação participativa é "uma modalidade nova de conhecimento coletivo do mundo e das condições de vida de pessoas, grupos e classes populares" (BRANDÃO, 1981, p. 43), porque traz o desafio de pesquisar e participar, de investigar e educar, permitindo, no processo de sua realização, articular teoria e prática (DEMO, 1992), tomando como ponto de partida os problemas reais (GÓMEZ; FLORES; JIMÉNEZ, 1999).

\section{Desenhos de mapas ambientais}

O desenho é a primeira manifestação da escrita humana, a primeira forma de expressão usada na infância. São as representações de como a criança lê o mundo, percebe a vida, comunica o que sente. Expressar-se através do desenho é colocar sua vida no papel, com toda a emoção (CARVALHO, 2000).

Por meio do desenho, a criança desenvolve noções de espaço, tempo quantidade, sequência, apropriando-se do próprio conhecimento, que é construído respeitando seu ritmo. Aprende também a função social da escrita, pois sua comunicação, feita através do desenho, pode ser compreendida por outras pessoas antes que ela aprenda a usar a escrita convencional para se comunicar (FERRERO; TEBEROSKY, 1990).

Quando desenha, a criança manifesta elementos advindos do domínio da observação sensível do real e da capacidade de imaginar e projetar, de significar. O desenho configura um campo de possibilidades, confrontando o real, o percebido e o imaginário. A observação, a memória e a imaginação são personagens que flagram esta zona de incerteza: o território entre o visível e o invisível (FRANCASTELL, 1975 apud DERDYK , 1989). 
É importante destacar, segundo a visão dessa autora, que o desenho lida com os elementos do espaço e também dos tempos - passado, presente e futuro. Há uma relação temporal entre a observação (presente), a memória (passado) e a imaginação (futuro). No ato de desenhar há várias manifestações mentais, como imaginar, lembrar, sonhar, observar, associar, relacionar, simbolizar, reapresentar e comunicar.

\section{A aula-passeio como um elemento promotor de ações educomunicativas}

A aula-passeio promove aquisições de novos conhecimentos, desenvolvendo habilidades de maneira contextualizada e significativa para o educando em uma constante interação com o meio. A instituição educacional é um lugar onde o aprendiz passa boa parte do seu tempo. Por isso, este artigo busca, também, refletir e mostrar em que medida a proposta da aula-passeio proporciona aos alunos uma interação lúdica, educomunicativa e motivadora no processo de ensino-aprendizagem.

É possível transformar as aulas em algo atraente, que torna o aluno um sujeito ativo e participante na construção de seu conhecimento. Para isso, torna-se necessário incluir no planejamento escolar o passeio cultural como um instrumento motivador ao aprendizado do educando. Freinet (1998) esboça que, tanto para o desenvolvimento de um ser como para o processo de ensino-aprendizagem, as condições exteriores desempenham um papel fundamental:

Desde que as condições exteriores sejam favoráveis à germinação, há uma força que desperta, cresce, agita o pão de trigo, que começa a escala para o esplendor do seu servir. (FREINET, 1998, p. 18).

De acordo com Mello (2003), a aula-passeio permite a ampliação das fontes de informação dos temas estudados na sala de aula, propiciando e ensinando uma atitude investigativa para os participantes. Freinet (1998) criou várias técnicas pedagógicas, uma das quais foi a aula-passeio, pois acreditava que o interesse da criança não estava na escola, mas no que acontecia fora dela. Assim, idealizava essa atividade com o objetivo de trazer motivação, ação e vida para o ambiente escolar.

A pedagogia freinetiana destaca a educação como um processo dinâmico que se modifica com o tempo e que está determinado pelas condições sociais. Dessa maneira, é preciso modificar a escola para adaptá-la à vida, para readaptá-la ao meio em um processo contínuo de transformação de dentro para fora (MELLO, 2003).

Com base nos postulados teóricos sociointeracionistas, que permitem ver as crianças como contribuidoras do processo educativo, principalmente no caso ambiental, este estudo articulou a construção de conhecimentos e uma ação educomunicativa que priorizou a participação das crianças, isto é, teve como referência a metodologia da pesquisa-ação participativa, ressaltada em Tozoni-Reis (2005). Neste caso, partiu-se do pressuposto de que a produção de conhecimentos sobre a realidade em estudo articula-se a um processo educativo e participativo para o enfrentamento da realidade que se deseja mudar.

Nessa perspectiva, ao interagirem com seu meio, conhecendo seu espaço para além da sala de aula, os alunos demonstraram estar mais motivados e cheios de novas informações para comunicar à sua família, amigos e professores sobre o que observaram durante a aula-passeio de forma oral e escrita, no momento em que desenharam em forma de mapa ambiental o que puderam observar em todo o trajeto percorrido. A expressão de sentimentos, carregados de saberes pessoais, pode ser o ponto de partida para que o professor inicie o seu empreendimento cognitivo no decorrer do ensino. 
Primeiramente os alunos foram convidados a construir desenhos sobre a APAJ, sendo esta uma forma de obter elementos diagnósticos sobre os conhecimentos e saberes das crianças envolvidas como agentes sociais da pesquisa. Todas participaram ativamente e disponibilizaram suas construções artísticas para a pesquisadora.

Para realizar a análise dos desenhos, fez-se uma leitura flutuante de todos os elementos produzidos em seu conjunto, seguindo-se o raciocínio da análise de conteúdo abordada por Bardin (2010). Em seguida, escolheu-se uma amostra representativa, conforme a sugestão de Gusmão (2003), o qual ressalta que os desenhos são verdadeiras "fábricas de imagens", nas quais se misturam as representações do momento presente, passado e das expectativas futuras. Os desenhos revelam e escondem. Assim sendo, o conhecimento da realidade concreta de seus produtores é fundamental para a interpretação analítica. As leituras dos desenhos feitas pelas crianças, as análises do conteúdo manifesto caracterizam-se como os pilares sobre os quais se assentará a análise do conteúdo latente, cujos contornos teóricos foram definidos nos parágrafos anteriores.

Intencionando que as intervenções de comunicação ambiental sobre a APAJ fornecessem os elementos direcionados nesse tipo de pesquisa, incluíram-se instrumentos para a coleta de dados no momento da aula-passeio, sendo estes um ponto de partida para avaliar, também, as concepções dos alunos oriundas de um aprofundamento da visualização do espaço em um momento lúdico de aprendizagem. A interação pedagógica subsidiou o estabelecimento de elementos didáticos para uma aula contextualizada, unindo conteúdos conceituais do dia a dia escolar e o conhecimento ambiental específico inerente àquela comunidade.

A escola foi mobilizada a participar da aula-passeio após consentimento da direção e apoio dos pais, que assinaram um termo autorizando o deslocamento das crianças em todo o perímetro da APAJ. Incluíram-se nesse processo participativo: 40 alunos, quatro professoras e uma funcionária da EMRAL. Incluindo a pesquisadora, somou-se um total de 46 pessoas participantes na excussão pedagógica sobre o ambiente.

Para concluir o processo de coleta dos dados da investigação-ação, foi realizada uma oficina sobre a APAJ com os alunos do $4^{\circ}$ e $5^{\circ}$ ano do turno vespertino.

Ao mobilizar o processo das ações interativas de sensibilização, procurou-se ouvir os alunos, em uma tempestade de ideias, direcionando para as impressões e observações que tinham antes e após o trajeto percorrido e possibilitando um contato mais aproximado uns com os outros e com a pesquisadora. No segundo encontro, foi solicitado aos alunos que criassem mapas ambientais, descrevendo o que foi observado.

As técnicas do mapeamento ambiental e da aula-passeio foram tomadas como sugestões metodológicas para a realização de atividades educomunicativas, envolvendo as questões socioambientais emergentes no contexto da APAJ.

Para proceder à leitura dos desenhos, optou-se por analisá-los em grupos, por meio de uma amostra, segundo a perspectiva defendida por Gusmão (2003), pois o conhecimento da realidade concreta de seus produtores é fundamental para a interpretação analítica.

Por último, foi realizada a criação de um jornal mural pelos alunos que participaram da oficina, para o conhecimento de toda a comunidade escolar.

\section{Resultados e discussões}

A análise das representações infantis sobre a APAJ e o entendimento do entorno da área geográfica delimitante constituíram dados de extrema riqueza conceitual. A visita à área estudada 
desencadeou a descoberta das características próprias da região: dunas, mangues, vegetação, mata atlântica, praia, lagoa, rio, área urbana e pontos turísticos.

A observação realizada pelos alunos foi importante para promover discussões sobre a relação homem-ambiente e ambiente natural-ambiente urbano. Essa abordagem também incentivou a ideia de construir um mapa ambiental da localidade, indicando o que foi observado no trajeto realizado durante a aula-passeio, a qual durou cerca de duas horas e contemplou todo o percurso em torno da APAJ. Paisagens visualizadas no percurso, entre elas dunas da APAJ (Figura 2) e área de mangue (Figura 3), receberam verbalizações enfáticas sobre a importância de se conservar não somente para as gerações atuais mas para aquelas que virão no futuro.

Com essas ações, os alunos realizaram, através do mapeamento ambiental, uma (re)leitura de seu ambiente cotidiano, começando pela própria escola e avançando gradualmente para os arredores.

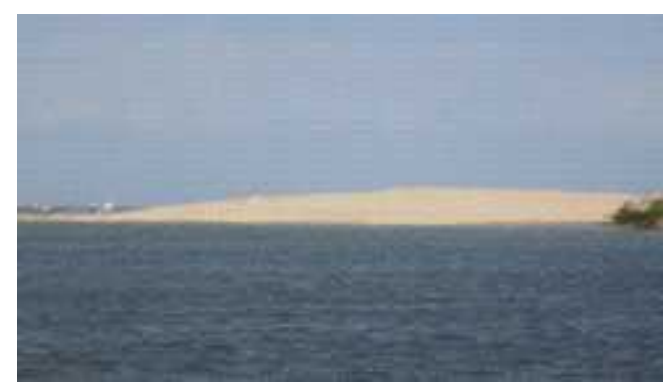

Figura 2. Dunas e Praia da APAJ.

Fonte: Jucicleide Souza

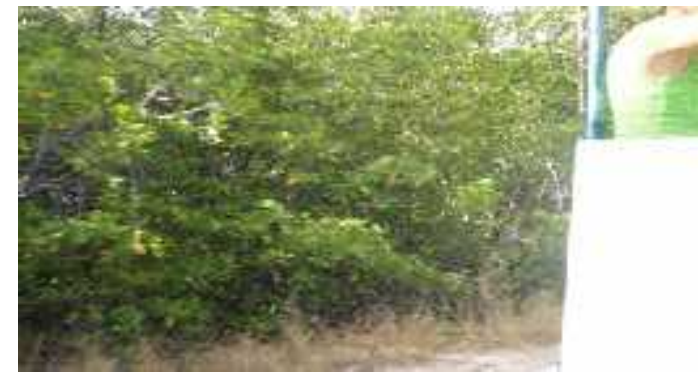

Figura 3. Mangue da APAJ.

Fonte: Jucicleide Souza

Durante o percurso da aula em campo, facilitada pelo uso de um carro adaptado para passeios infantis (Figuras 4 e 5), os alunos tiveram a oportunidade de observar o bairro, visualizando todo o cenário, composto por pessoas, casas, centros comunitários, paisagens naturais, ruas, animais, comércios e vegetação. Tudo o que foi observado foi registrado pelos alunos e reportado em discussões na sala de aula.

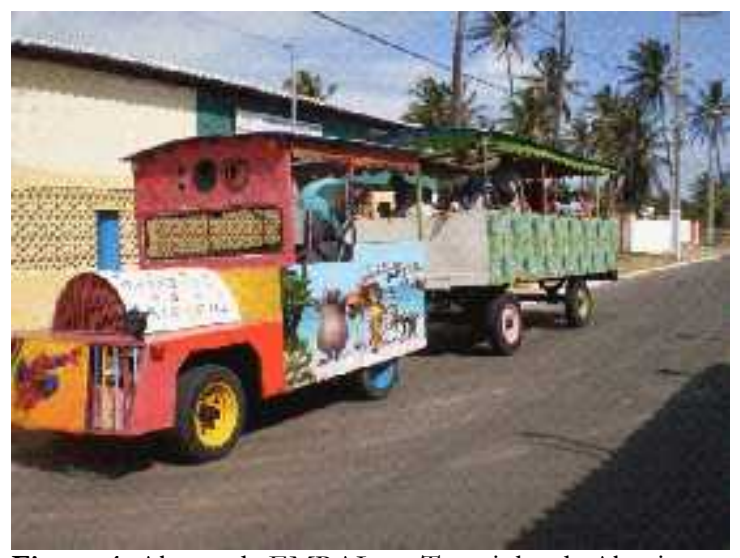

Figura 4. Alunos da EMRAL no Trenzinho da Alegria.

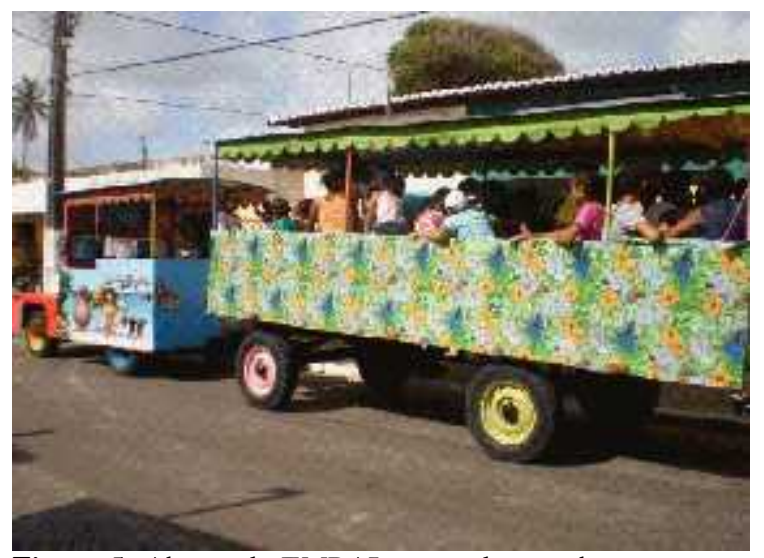

Figura 5. Alunos da EMRAL tomando seus lugares para a 
Após uma primeira leitura do ambiente, outros aspectos locais foram investigados. Assim, o mapeamento ambiental contribuiu para ampliar a compreensão dos educandos sobre o ambiente em que vivem. Essa proposta, segundo Meyer (1991, 1992), articula investigação e ação educativa, pois faz um levantamento ambiental, um diagnóstico do ambiente segundo a percepção dos envolvidos, que identificam o espaço social, histórico, político e cultural e, ao mesmo tempo, apropriam-se do conhecimento produzido, isto é, são também sujeitos das ações educativas ambientais.

É importante destacar que a construção dos mapas pelos alunos (Figuras 6 e 7), como proposta educativa, não tem o compromisso de reprodução do ambiente real, mas do ambiente percebido por eles. Trata-se, então, de uma "leitura do ambiente".

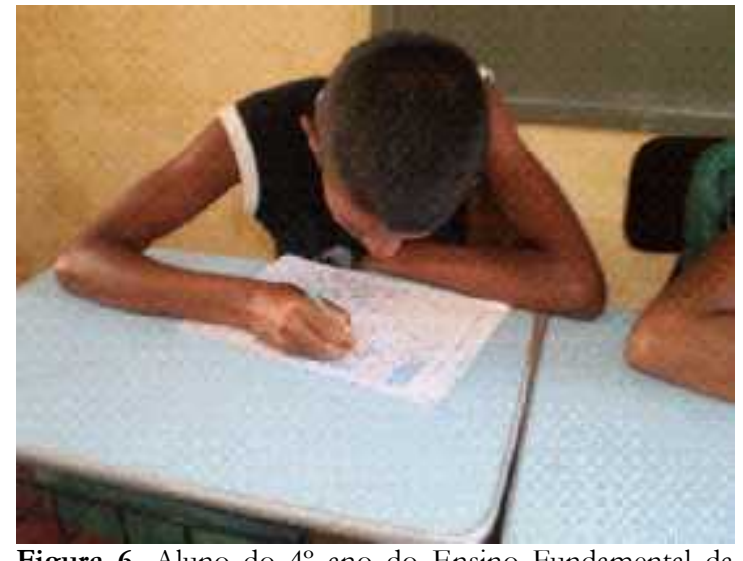

Figura 6. Aluno do $4^{\circ}$ ano do Ensino Fundamental da EMRAL produzindo o mapeamento ambiental.

Fonte: Jucicleide Souza.

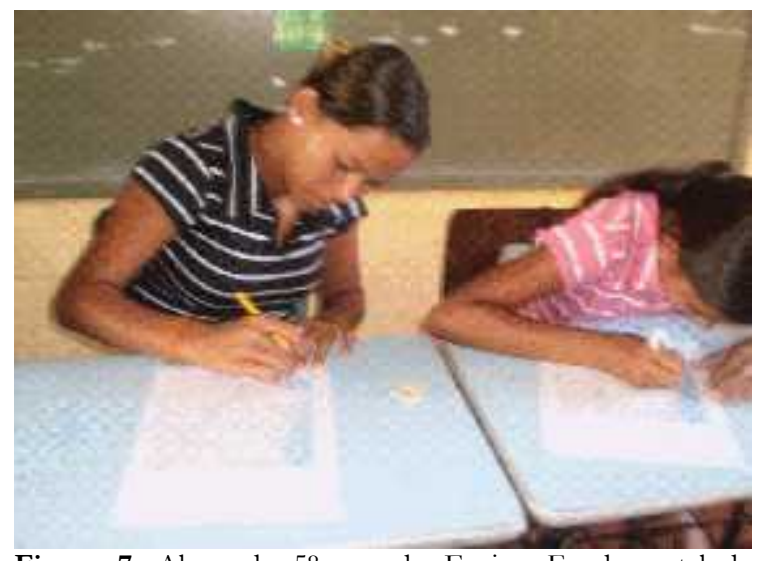

Figura 7. Aluna do $5^{\circ}$ ano do Ensino Fundamental da EMRAL produzindo o mapeamento ambiental. Fonte: Jucicleide Souza.

A terceira e última fase da pesquisa foi a culminância de todas as ações com a criação de um jornal mural, para comunicar a toda a comunidade vinculada à escola o produto das observações, do 
que foi refletido e discutido, como também as reclamações e sugestões emergidas no decorrer das atividades dentro e fora da escola.

Os próprios alunos criaram e escolheram o nome do jornal, matérias a serem abordadas, redação e edição. No processo de confecção do jornal houve intervenção de uma professora/comunicadora, o que está de acordo com a concepção de Vygotsky (2003) de que "o professor desempenha um papel ativo no processo de educação: modelar, cortar, dividir e entalhar os elementos do meio para que estes realizem o objetivo buscado". A espontaneidade e alegria demonstradas foram percebidas tanto nos professores quanto nos alunos envolvidos (figuras 8 e 9).

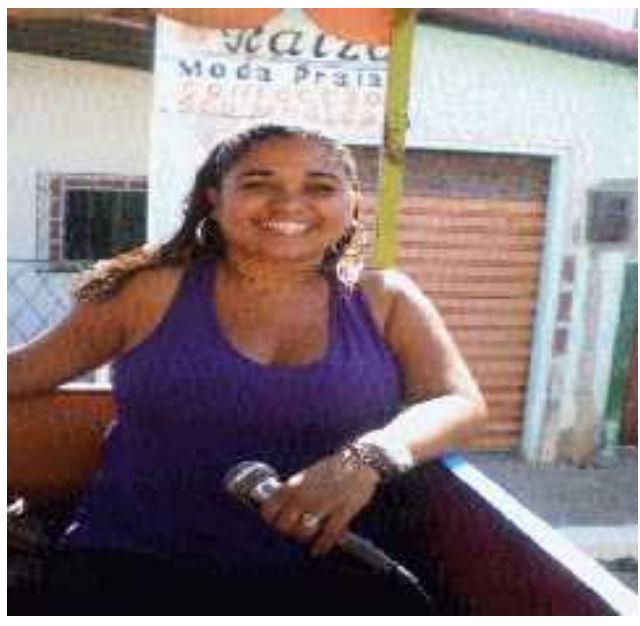

Figura 8. Professora/comunicadora, guia no percurso (moradora da APAJ). Fonte: Jucicleide Souza.

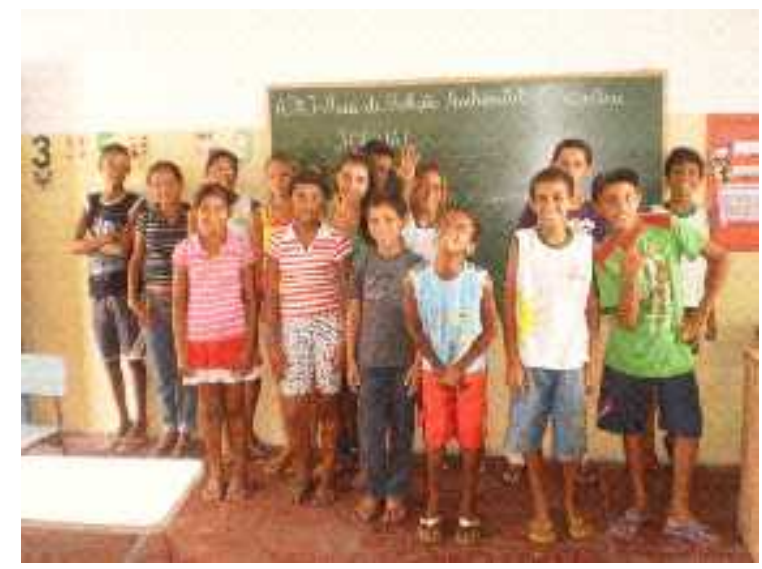

Figura 9. Alunos do $4^{\circ}$ e $5^{\circ}$ ano participantes da pesquisa e produtores de um jornal mural educomunicativo. Fonte: Jucicleide Souza.

O início das ações foi marcado pelas atividades interativas com a formação de pequenos grupos de alunos (figuras 10 e 11), preocupação fundamental do processo de pesquisa participante e também dos processos educativos voltados para promover a participação das crianças na aprendizagem.

Entre as causas históricas das ações predatórias da humanidade, está o caráter individualista com que os diferentes atores sociais se apropriam da natureza. Portanto, parte do processo educativo trabalha com a formação de grupos coletivos e cooperativos. 


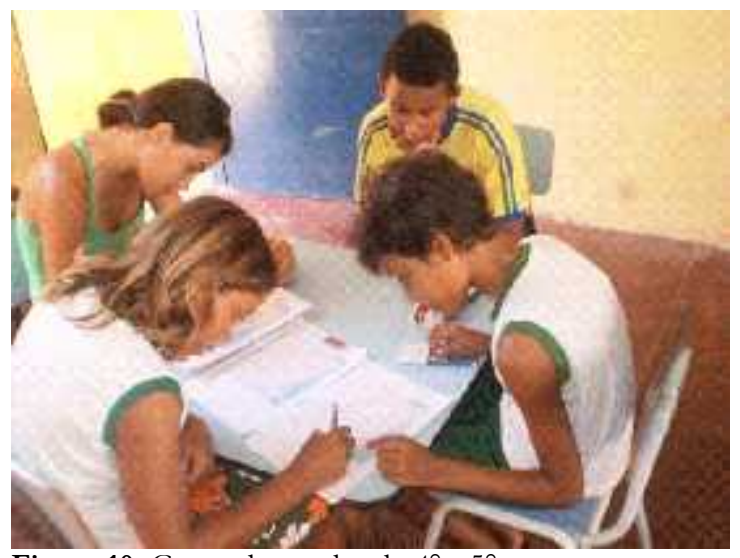

Figura 10. Grupo de estudos do $4^{\circ}$ e $5^{\circ}$ ano Fonte: Jucicleide Souza.

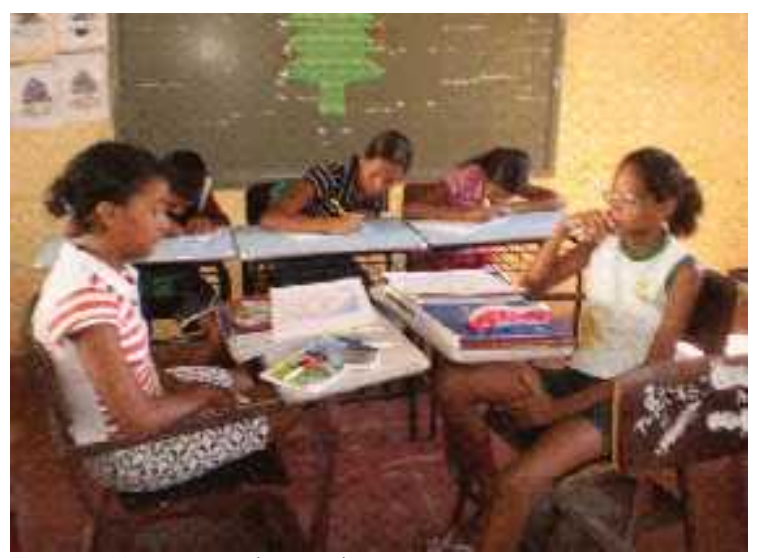

Figura 11. Grupos de estudo.

Fonte: Jucicleide Souza.

Os registros dos mapas mentais mostraram que as ações educomunicativas e seus resultados foram significativos, pois indicaram a necessidade de um olhar cuidadoso, capaz de perceber os grandes traços e também os pequenos detalhes da APAJ. Procurou-se, também, enxergar por detrás dos desenhos as ausências e os silêncios, assim como os aspectos que não estão no quadro e cujas revelações constituem parte importante desta análise (MORAES SILVA; MELO; APPOLINÁRIO, 2007).
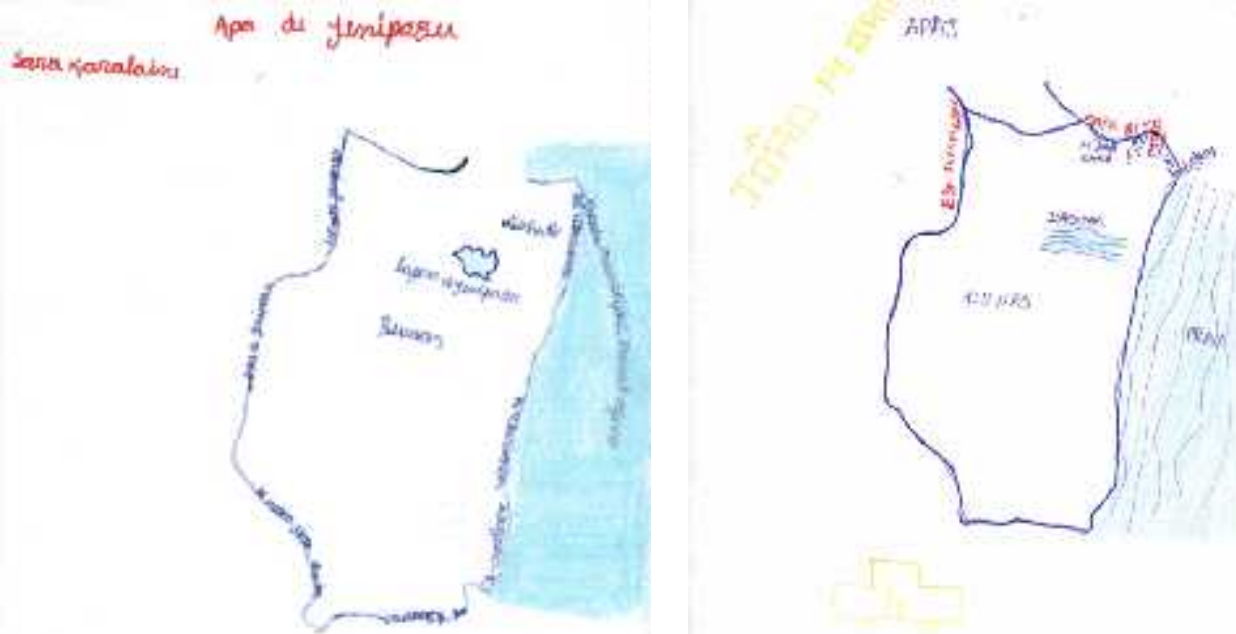

Figura 12. Representações de mapas da APAJ detalhadas por dois alunos envolvidos na pesquisa. Desenhos realizados pelos alunos da EMRAL.

Observou-se que há uma predominância de elementos em todos os desenhos: a praia, a lagoa de Jenipabu e as dunas. Esses três elementos naturais são, provavelmente, os que mais representam a APAJ para essas crianças. Vale destacar que no trajeto percorrido na aula-passeio a lagoa de Jenipabu não foi visitada por estar fechada à visitação. Nesse sentido, percebe-se o quanto tais aspectos constituem para as crianças o mapa ambiental da APAJ, ainda que essa área não seja composta apenas por esses três elementos representados.

Além disso, dos 15 mapas ambientais produzidos, sete trazem a representação da EMRAL, indicando a importância desse espaço para esses alunos. Em relação ao aspecto espacial, apenas 
quatro alunos tiveram dificuldades em localizar da maneira mais aproximada do real suas representações do meio.

É indiscutível como a prática aproxima os alunos do conhecimento sobre o real. Mesmo sendo moradores da área, eles não a conheciam com propriedade.

Sobre trabalhos dedicados ao estudo das representações do ambiente, destaca-se Reigota (1985), que considera a noção de meio ambiente como uma representação social, isto é, aquilo que as pessoas compreendem sobre um conceito de acordo com suas experiências cotidianas, em geral, carregadas de distorções e ideologias, portanto, distanciadas dos conceitos científicos.

Segundo Porto-Gonçalves (1990), a dicotomia entre homem e natureza foi consolidada na civilização industrial capitalista do Ocidente, identificando os conceitos e conhecimentos fragmentados como colaboradores dessa percepção dicotomizada. O ambiente como um espaço construído, modificado pelas relações sociais precisa, portanto, ser estimulado em todas as propostas educativas (MEYER, 1991). Assim, as crianças podem, desde pequenas, ler e reler o ambiente em que vivem, percebê-lo não mais como natureza intocada, mas como um ambiente modificado pelas relações sociais estabelecidas pelos sujeitos.

\section{Conclusões}

A compreensão, o diálogo, a afetividade e as concepções do professor nas interações pedagógicas são aspectos fundamentais para a eficácia de um ensino contextualizado numa perspectiva nova de sensibilização ambiental.

A comunidade escolar inserida na APAJ, após participar do passeio cultural (aula-passeio), expressou ter vivenciado e construído conhecimentos novos sobre a biodiversidade existente ao seu redor e sentiu-se grata por participar, pela primeira vez, de uma atividade nessa perspectiva educativa no ambiente em que vive e estuda.

A aproximação maior dos alunos com seu meio proporcionou uma experiência ímpar, no aspecto de sentirem-se participantes daquele ambiente, conhecendo-o através de vivências reflexivas.

Ao retornarem à escola, percebemos a empolgação e ansiedade desses alunos para compartilharem com todos aquela experiência, gerando a necessidade da criação de um jornal mural, um meio educomunicativo a ser elaborado pelos participantes da pesquisa.

O jornal mural foi uma atividade educomunicativa caracterizada como a síntese das ações desenvolvidas na APAJ, por ter sido criado, elaborado e editado pelos próprios alunos, contando com a mediação do professor/comunicador.

O envolvimento dos alunos com o meio possibilitou o reconhecimento da área e a identificação como moradores de um espaço de grande importância (APAJ) como consequência do estreitamento do espaço de aprendizagem fora e dentro da sala de aula.

É importante destacar que as ações educativas relativas ao meio ambiente terão maior possibilidade de êxito se, além de considerarem o entorno do espaço escolar, envolverem a comunidade.

Atividades educomunicativas diversas devem ser implementadas na escola, tendo em vista fortalecer ações voltadas à Educação Ambiental como eixo transversal rico de conteúdos voltados à conservação do meio onde vivem os alunos.

Embora exija do professor maiores capacidades para conduzir o processo de ensinoaprendizagem, é na perspectiva de uma aprendizagem contextualizada com o ambiente que se atingirá o real objetivo desejado por todos que advogam a inserção da Educação Ambiental desde os primeiros anos de escolarização. 
A atividade educativa realizada na APAJ foi um ponto de partida para o processo de envolvimento da comunidade escolar, especificamente alunos e professores, vivenciando uma experiência didática que enriqueceu a aprendizagem.

Nesse sentido, foram atingidos objetivos educativos, como a formação de habilidades cognitivas e sociais, a formação cidadã, a construção de conceitos científicos, a apropriação de conteúdos culturais e a formação de uma consciência favorável à preservação do meio ambiente.

A criação permanente de um meio de comunicação interligado às práticas educativas no ambiente escolar foi valiosa nesse percurso de formação. Para isso, outra necessidade emerge nesse cenário - o envolvimento dos professores com a proposta de desenvolver na escola práticas educomunicativas, como a elaboração de jornais-murais.

Desse modo, as escolas inseridas em Unidades de Conservação Ambiental de uso sustentável devem considerar um diagnóstico acerca dos conhecimentos ambientais veiculados em seu âmbito e em seu entorno, para que ações educomunicativas tornem-se adequadamente direcionadas ao percurso do ensino-aprendizagem e assim todos os profissionais envolvidos possam receber a real atenção no sentido de desenvolver ações em prol da conservação do meio de forma mais efetiva.

\section{Referências}

BARDIN, Laurence. Análise de conteúdo. 3. ed., São Paulo: Edições 70, 2010.

BELLONI, Maria Luiza. Educação à distância. 5. ed. Campinas, SP: Autores Associados, 2008.

BRANDÃO, Carlos Rodrigues. Pesquisa participante. 3. ed. São Paulo: Brasiliense, 1981.

- A pergunta a várias mãos: a experiência da pesquisa no trabalho do educador. São Paulo: Cortez, 2003.

BRASIL. Secretaria de Educação Fundamental. Parâmetros curriculares nacionais: meio ambiente, saúde. Ensino de primeira à quarta série. Brasília, DF: SEF, 1997. 128 p.

.ENCEA - Estratégia Nacional de Comunicação e Educação Ambiental no Âmbito do Sistema Nacional de Unidades de Conservação. Brasília, DF: Ministério do Meio Ambiente, 2009. (Cartilha para Consulta Pública).

CARVALHO, Teresinha Véspole. $O$ desenho $e$ a aprendizagem. 2000. Disponível em: < http://www.psicopedagogia.com.br/artigos >. Acesso em: 08 jan. 2011.

CAZOTO, Juliana Lacorte; TOZONI-REIS, Marília Freitas de Campos. Construção coletiva de uma trilha ecológica no cerrado: pesquisa participativa em educação ambiental. Ciência e Educação [online], Bauru, v. 14, n. 3, p. 575-582, 2008.

DARSIE, Marta Maria Pontin. Perspectivas Epistemológicas e suas Implicações no Processo de Ensino e de Aprendizagem. Cuiabá: Uniciências, 1999.

DEL CUETO, Ana María. (Org.). Lo grupal 2. Bueños Aires: Búsqueda, 1985.

DEMO, Pedro. Metodologia cientifica em ciências sociais. 2. ed. São Paulo: Atlas, 1992. 
Pesquisa Participante - saber pensar e intervir juntos. Brasília: Liber Livro, 2004.

DERDYK, Edith. Formas de pensar o desenho, desenvolvimento do grafismo infantil. São Paulo: Scipione, 1989.

DI LEO, Joseph H. A interpretação do desenho infantil. Porto Alegre: Artes Médicas, 1991.

DUARTE, Newton. Educação escolar, teoria do cotidiano e a escola de Vygotsky. São Paulo: Autores Associados, 1999.

FERRERO, Emilia; TEBEROSKY, Ana. A psicogênese da lingua escrita. Trad. Diana Myriam Lichtenstein, Liana Di Marco e Mário Corso. Supervisão da tradução: Alfredo Néstor Jerusalinsky psicanalista. 3. ed. Porto Alegre: Artes Médicas, 1990.

FERRÉS, Joan. Video e Educação. Porto Alegre: Artes Médicas, 1996.

FREINET, Célestin. A Educação do Trabalho. São Paulo: Martins Fontes, 1998.

FREIRE, Paulo. A educação como prática de liberdade. Rio de Janeiro: Paz e Terra, 1967. - A importância do ato de ler. São Paulo: Cortez/Autores Associados, 1985.

FREITAS, Maria Teresa de A. As apropriações do pensamento de Vygotsky no Brasil: um tema em debate. Psicologia da Educação, n.10-11, p. 9-28, 2000.

GÓMEZ, Gregorio Rodríguez; FLORES, Javier Gil; JIMÉNEZ, Eduardo García. Metodología de la investigación cualitativa. Málaga: Aljibe, 1999.

GUSMÃO, Neusa Maria Mendes de. Infância e velbice. Campinas: Alínea, 2003.

INSTITUTO DE DESENVOLVIMENTO SUSTENTÁVEL E MEIO AMBIENTE DO RIO GRANDE DO NORTE - $\quad$ IDEMA. Disponível em: < http://www.idema.rn.gov.br/contentproducao/aplicacao/idema/unidades de conservacao/gerados/unida des de conservacao.asp $>$. Acesso em: 23 maio 2010.

LANE, Silvia T. M. O processo grupal. In: LANE, Silvia T. M.; CODO, Wanderley (Org.). Psicologia Social: o homem em movimento. São Paulo: Brasiliense, 1984.

LEFF, Enrique. Saber ambiental: sustentabilidade, racionalidade, complexidade, poder. Petrópolis: Vozes, 2001.

MARTIRANI, Laura Alves. Videoprodução e educação: experiências e reflexões. Vivência, Natal, n. 29, p.361-366, 2005.

MELLO, Suely Amaral. Aula passeio. Botucatu, 2003. (Apostila).

MEYER, Mônica Ângela de Azevedo. Educação ambiental: uma proposta pedagógica. Em Aberto, Brasília, v. 10, n.49, p. 40-45, jan./mar. 1991.

Ecologia faz parte do espaço cotidiano. AMAE Educando, n. 225, p. 13-20, 1992. 
MORAES SILVA, Maria Aparecida de; MELO, Beatriz Medeiros de; APPOLINÁRIO, Andréia Peres. A família tal como ela é nos desenhos de crianças. RURIS, Campinas, v. 1, n. 1, p. 105-155, mar. 2007.

NASCIMENTO, Maria Vitória Élida do; ARAÚJO DE ALMEIDA, Elineí. Estudo das percepões e avaliação de interações educativas voltadas ao meio ambiente em escolas de uma unidade de conservação do Rio Grande do Norte - Brasil. Ambiente \& Educação, v. 17, n. 2, 2012. Disponível em: <www.seer.furg.br/ambeduc/article/download/2579/2164>. Acesso em: 23 maio 2011.

PIAGET, Jean. O Nascimento da inteligência na criança. 2. ed. Rio de Janeiro: Zahar, 1975.

PORTO-GONÇALVES, Carlos Walter. Os (des)caminhos do meio ambiente. 2. ed. São Paulo: Contexto, 1990.

REGO, Tereza Cristina. Vygotsky: uma perspectiva histórico-cultural da educação. Rio de Janeiro: Vozes, 1999.

REIGOTA, Marcos. Meio ambiente e representação social. São Paulo: Cortez, 1985.

RODRIGUES, Ligia Maria da Silva. Mapeamento ambiental na educação infantil: descobrindo nosso bairro. 2005. Trabalho de Conclusão de Curso (Licenciatura em Ciências Biológicas) - Instituto de Biociências, Universidade Estadual Paulista, Botucatu, 2005.

SOARES, Ismar de Oliveira. Gestão comunicativa e educação: caminhos da Educomunicação. Comunicaşão \& Educação, São Paulo, ano 8, n. 23, p. 16-25, jan./abr. 2002.

THIOLLENT, Michel. Notas para o debate sobre pesquisa-ação. In: BRANDÃO, Carlos Rodrigues (Org.). Repensando a Pesquisa Participante. São Paulo: Brasiliense, 1984.

TORRES, Denise de Freitas. Etnoecologia nas APAs Genipabu e Bonfim/Guaraíras - RN: uma análise da relação entre a biodiversidade e as populações tradicionais. 40 p. Trabalho de Conclusão de Curso - Universidade Federal do Rio Grande do Norte, Natal, 2008.

TOZONI-REIS, Marília Freitas de Campos. Compartilhando saberes: pesquisa e ação educativa ambiental. In: FERRARO JÚNIOR, Luiz Antonio (Org.). Encontros e Caminhos: formação de educadores ambientais e coletivoseducadores. Brasília: Ministério do Meio Ambiente, Diretoria de Educação Ambiental, 2005. p. 25-30.

. Educação ambiental: naturez̧a, rąãa e história. Campinas: Autores Associados, 2004.

VYGOTSKY, Lev S. A formação social da mente. São Paulo: Martins Fontes, 1984.

. Pensamento e Linguagem. São Paulo: Martins Fontes, 1987.

. Psicologia pedagógica. Porto Alegre: Artmed, 2003.

Artigo recebido em 09/11/2012

Artigo aprovado em 27/06/2013 